\title{
Family-Centered Primary Care for Older Adults with Cognitive Impairment
}

\author{
Melissa L. Welch ${ }^{1,3}$ (D) Jennifer L. Hodgson ${ }^{1}\left(\mathbb{D} \cdot\right.$ Katharine W. Didericksen $^{1}\left(\mathbb{D} \cdot\right.$ Angela L. Lamson $^{1}(\mathbb{D} \cdot$ \\ Thompson H. Forbes ${ }^{2} \mathbb{0}$
}

Accepted: 1 November 2021 / Published online: 15 November 2021

(c) The Author(s), under exclusive licence to Springer Science+Business Media, LLC, part of Springer Nature 2021

\begin{abstract}
Cognitive impairment (e.g. dementia) presents challenges for individuals, their families, and healthcare professionals alike. The primary care setting presents a unique opportunity to care for older adults living with cognitive impairment, who present with complex care needs that may benefit from a family-centered approach. This indepth systematic review was completed to address three aims: (a) identify the ways in which families of older-adult patients with cognitive impairment are engaged in primary care settings, (b) examine the outcomes of family engagement practices, and (c) organize and discuss the findings using CJ Peek's Three World View. Researchers searched PubMed, Embase, and PsycINFO databases through July 2019. The results included 22 articles out of 6743 identified in the initial search. Researchers provided a description of the emerging themes for each of the three aims. It revealed that family-centered care and family engagement yields promising results including improved health outcomes, quality care, patient experience, and caregiver satisfaction. Furthermore, it promotes and advances the core values of medical family therapy: agency and communion. This review also exposed the inconsistent application of family-centered practices and the need for improved interprofessional education of primary care providers to prepare multidisciplinary teams to deliver family-centered care. Utilizing the vision of Patient- and Family-Centered Care and the lens of the Three World View, this systematic review provides Medical Family Therapists, healthcare administrators, policy makers, educators, and clinicians with information related to family engagement and how it can be implemented and enhanced in thecare of patients with cognitive impairment.
\end{abstract}

Keywords Family-centered care · Primary care · Cognitive impairment · Three World View · Systematic review

Cognitive impairment (CI; e.g. dementia) impacts up to two-thirds of the American population (Hale et al., 2020) and $20 \%$ of the older adult (i.e. individuals aged 65 and older) population (Langa \& Levine, 2014). While CI has the potential to impact individuals across the lifespan due to a variety of causes (e.g. brain injury), the scope of this article is focused on aging-related conditions (e.g. Alzheimer's disease, vascular dementia) as the risk for developing these

Melissa L. Welch

welchm@ufl.edu

1 Department of Human Development and Family Science, East Carolina University, Greenville, NC, USA

2 Department of Advanced Nursing Practice and Education, East Carolina University, Greenville, NC, USA

3 Department of Community Health and Family Medicine, University of Florida College of Medicine, Gainesville, FL, USA conditions increases with age and is much more common in adults 65 and older (Smith \& Wright, 2021). Older-adult patients with cognitive impairment utilize healthcare services more often than their non-cognitively impaired peers (St-Hilaire, 2017) and families frequently participate in their care (Wolff et al., 2016). Additionally, a recent survey of primary care providers (PCP) found that adults aged 65 and older make up $40 \%$ of primary care visits and at least $13 \%$ of those patients have a dementia diagnosis (Alzheimer's Association, 2020). This results in PCPs addressing CI with patients and caregivers in their practice on an almost daily basis.

Unfortunately, families and healthcare providers have reported dissatisfaction and frustration with poor communication and inefficient execution of assessment and diagnostic processes for CI (Pathak \& Montgomery, 2015). Existing literature has also emphasized the need for more effective assessment and improved diagnostic efficiency of 
CI (Seematter-Bagnoud \& Büla, 2018). Providers identified insufficient time and support for these patients as primary concerns in their practice (Skibitsky, 2016). Medical family therapists can help to reduce such issues by collaborating with patients and families to identify and conceptualize major concerns and goals for treatment and facilitate clear communication with healthcare team members (Hodgson et al., 2014; McDaniel et al., 1992, 2014a).For example, one study found that nonphysician healthcare providers (e.g. family counselors, resource centers, pharmacists) helped to promote appropriate and timely diagnostic evaluations given their access to patients and families in community and residential care settings (Maslow \& Fortinsky, 2018). However, a thorough understanding of the care strategies that successfully facilitate the assessment and diagnostic processes of CI in primary care and their associated outcomes is missing.

The implementation of patient- and family-centered care (PFCC; Johnson \& Abraham, 2012), may provide hope for improving the care of patients and families facing CI (Jennings et al., 2017). Yet, despite recommendations for healthcare systems to implement PFCC from notable organizations including the American Medical Association (AMA, 2016; Millenson et al., 2016), the absence of existing standard protocols results in healthcare providers engaging families according to their discretion (Sivananthan et al., 2013). Consequently, the way families are engaged (e.g. phone calls, in-person visits, decision making, care training) varies greatly across healthcare settings (e.g. primary care, nursing homes, hospitals) and among providers (e.g. family physicians, geriatric specialists). The development of clearly defined evidence-based standard practice requires an improved understanding of the evidence for PFCC with CI and its associated outcomes.

\section{Patient- and Family-Centered Care (PFCC): A Vision}

PFCC is designed to ensure that family engaged health care becomes the rule, rather than the exception (as is currently the case). The practice of PFCC promotes collaborative and direct communication between the professional healthcare team, patients, and families (i.e. patientidentified support persons, which could include relatives, friends, neighbors, and/or caregivers). The PFCC vision of care builds upon four fundamental beliefs and values: (a) dignity and respect, (b) information sharing, (c) participation, and (d) collaboration (Johnson \& Abraham, 2012). These concepts frame how to approach the treatment of patients and families in the healthcare system to improve experiences and outcomes of care (Institute for PFCC, n.d.). Moreover, they promote and advance the core values of medical family therapy (i.e. agency and communion; McDaniel et al., 1992). Stakeholders (e.g. patients, families, providers, administrators) achieve these shared values when they work collaboratively across the full continuum of care (Institute for PFCC, n.d.).

Researchers have found significant benefits when implementing PFCC in hospital settings such as increased family satisfaction in adult intensive care units (Wong et al., 2019). Furthermore, the Agency for Healthcare Research and Quality (AHRQ, 2011) encourages family engagement to improve patient care quality across settings, including primary care. The Institute of Medicine (IOM, 2001) also identified PFCC as one of the ways to improve healthcare quality in Crossing the Quality Chasm, emphasizing the value of relationships and family perspectives. However, two decades later, widespread implementation of PFCC in primary care remains uncommon (Kokorelias et al., 2019). Additional research is needed to understand how to successfully implement PFCC with older adults exhibiting CI.

\section{Unique Challenges of Cognitive Impairment with Older Adults}

As noted earlier, CI can potentially impact individuals of all ages, but risk for developing $\mathrm{CI}$ increases with age and becomes a greater concern for adults aged 65 and older (Alzheimer's Association, 2020). Older adults with CI commonly struggle with memory, learning, concentration, and/or decision making (CDC, 2014). Additionally, they may struggle to describe their symptoms to healthcare providers and experience decreased comprehension of care instructions, which can negatively impact treatment and treatment adherence (Han et al., 2011). These communication challenges create a need for engaging support persons in the healthcare process, particularly when interacting with PCPs who need to also address other comorbid conditions (e.g. diabetes, high blood pressure, depression) that often accompany CI (Bunn et al., 2016).

In addition to clinical challenges, operational and financial barriers can also make care for older adults with CI difficult. For example, lack of access to specialists (e.g. geriatric psychiatrist, neurologists) in rural areas or long wait times for specialists can increase the burden of care in primary care settings (Maslow \& Fortinsky, 2018). Older adults may also have trouble obtaining necessary care if funding sources (e.g. Medicare coverage) are not available or sufficient due to high out-of-pocket costs (Garfield et al., 2015). These potential barriers make it increasingly important for primary care settings to be prepared to care for older adults with $\mathrm{CI}$ and their families. 


\section{Addressing $\mathrm{Cl}$ in Primary Care}

It is important to note that most patients first discuss memory and thinking problems with PCPs (Alzheimer's Association, 2017). Additionally, more than 30 percent of older adults, particularly those who have more extensive health needs, bring a family member with them to routine primary care visits (Wolff \& Roter, 2011). This presents opportunities for healthcare teams to engage with family members of patients who have CI. This may facilitate family-centered treatment at earlier stages of care, which presents opportunities for improved health outcomes, reduced costs, and increased satisfaction of caregivers, patients, and providers.

Early detection of CI needs improvement as CI goes unrecognized more than half the time in patients aged 70 or older (Kotagal et al., 2015). Additionally, patients experience an average delay of three years from the arise of dementia symptoms to the time of diagnosis (Alzheimer's Association, 2014). Reasons for this delay vary and although some family members may be reluctant to share their concerns when symptoms first develop, it is also likely that many families do not have opportunities to share their concerns with the healthcare team (Boise, 2006). Earlier detection of CI leads to improved patient satisfaction, greater medical treatment adherence, decreased utilization of unnecessary care, and lower healthcare costs (Lin et al., 2013). This is significant given that patients with CI generate higher treatment costs due to complex care within nursing facilities (Hurd et al., 2013) and elevated hospitalizations rates, which are more than tripled for individuals with CI compared to patients without cognitive problems (Alzheimer's Association, 2009). Providing appropriate care to these patients and their families at the primary care level may help to alleviate these costs and negative health outcomes.

\section{Three World View Theoretical Framework}

The Three World View (Peek, 2008) provides a foundation for conducting research in a way that honors the vision of PFCC and attends to the three worlds of successfully transforming healthcare practices: clinical, operational, and financial worlds. Viewing the research and outcomes of PFCC within a Three World View framework provides a way of building and implementing a PFCC strategy that will benefit all stakeholders. Within our systematic review, health outcomes are examined and discussed using the three worlds: clinical, operational, and financial. These worlds provide a means for organizing the evidence for implementation of care strategies such as family engagement practices (Miller et al., 2009). We use a fourth world of education to discuss the preparation of medical providers and healthcare teams, which is equally necessary for successful implementation of
PFCC. The Three World View has been used extensively in the research of integrated care, such as with the examination of operational factors that influence implementing mental health into primary care (Benzer et al., 2012), competencies for psychologists' practice in primary care (McDaniel et al., 2014b), and payment reform (Miller et al., 2017). The lens is useful for these purposes as it provides a language communicable across levels within a healthcare system from clinicians to administrators.

Combining the vision of PFCC and the lens of the Three World View provides a systemic foundation and plan for reviewing the existing outcomes literature on family engagement practices with older adults experiencing CI. It is vital to understand the definition of patient and family engagement as patients, families, their representatives, and health professionals working together throughout the healthcare system to improve health outcomes and the system (Carman et al., 2013). The explicit use of "PFCC" and "family engagement" in our manuscript refer to care in which family members are actively and intentionally engaged. This is critical to the success of this review and the value of its results. Recognizing the unique challenges that CI poses to patients, families, and healthcare systems provides Medical Family Therapists and other healthcare professionals a starting point for understanding the care necessary to effectively address and improve assessment, diagnosis, and treatment of CI in older adults.

\section{Aims}

Existing PFCC research primarily focuses on infant, child, and adolescent patient populations in settings such as hospitals and specialty care (Kokorelias et al., 2019). An alarming gap in the literature persists regarding family engagement practices for older adults with CI in primary care where many of these patients are routinely treated (Wubbeler, 2017). To address this gap, we established three primary aims of this study: (a) identify the ways in which families of older-adult patients with $\mathrm{CI}$ are engaged in primary care settings, (b) examine the outcomes of family engagement practices, and (c) organize and discuss the findings using CJ Peek's Three World View (2008).

\section{Methods}

\section{Design and Research Question}

This review followed Cooper's (2017) seven-step model for conducting systematic reviews. It also adhered to the PRISMA (Preferred Reporting Items for Systematic Reviews and Meta-Analyses) standards of quality for 
reporting systematic reviews (Moher et al., 2009). This process involved the following steps: (a) formulation of the problem, (b) development of the research question, (c) systematic review of the literature, (d) data extraction, (e) quality appraisal of included studies, (f) analysis, and (g) synthesis of the findings. The following research question guided this systematic review: What are the clinical, operational, and financial outcomes of family-centered primary care with older-adult patients experiencing CI?

\section{Search Strategy}

In July 2019, authors comprehensively searched three databases (i.e. PubMed, Embase, and PsycINFO) for literature published at any date (up to the time of the search) that met the search criteria. The lead researcher collaborated with a library scientist to select databases that could identify national and international literature within health and social science disciplines. Databases were chosen primarily for the size of the database in journal coverage. It is important to note that some relevant databases (e.g. CINAHL and Web of Science) were not used given the unlikely chance that they would result in unique studies compared to those found by PubMed, Embase, and PsycINFO. The library scientist assisted in defining key search terms (e.g. Three World View, family-centered care, older adults, primary care, cognitive impairment), MeSH terms (medical subject headings in PubMed; e.g. "dementia" [mesh]), and syntax utilized within each database. A full list of search terms and syntax are available upon request.

Articles were included in this review if they met the following criteria: (a) original research, (b) published in the English language, (c) explicitly and clearly defined family engagement practice, (d) occurred within a primary care setting, (e) the patients had existing or suspected diagnosis of CI, and (e) the patients were aged 65 or older. As noted above, family could include any patient-identified support person including relatives, friends, neighbors, and/or caregivers. Family engagement was defined as the active and intentional engagement of these patient-identified support persons. Primary care settings included internal medicine and family medicine, as supported by previous research (Bertakis \& Azari, 2011). Studies could be qualitative, quantitative, or mixed methods in nature. Omission of gray literature (e.g. conference and poster presentations, magazine articles, government reports) was necessary given the largescale nature of the review and resource constraints. Gray literature also poses a challenge due to the lack of a formal peer-review process which can limit the quality of included studies. Final analyses did not include systematic reviews, meta-analyses, and literature reviews. The PRISMA diagram (Fig. 1) illustrates the process used by co-researchers to identify and screen the articles admitted into the review.

\section{Data Extraction, Analysis, and Synthesis}

The methodological rigor of each study was critically appraised by two co-researchers using a tool by Hawker, et al. (2002) that scored nine items from 1 (very poor) to 4 (good): (a) abstract and title, (b) introduction and aims, (c) method and data, (d) sampling, (e) data analysis, (f) ethics and bias, (g) findings/results, (h) transferability/generalizability, and (i) implications and usefulness. Scoring criteria were clearly defined by the assessment tool. Each study was then given a summative score that fell within four ranges: 1-9 (very poor), 10-18 (poor), 19-27 (fair), and 28-36 (good). All studies had scores greater than 28 except for one study falling in the "fair" range due to brevity and a lack of detailed reporting, which may have been attributed to article length restrictions. Given the value of all findings, no studies were excluded based on quality appraisal rating.

Upon the final selection of included articles $(N=22)$, the lead researcher extracted information to facilitate analysis and synthesis of the methods and results. Co-researchers screened titles and abstracts of all identified records using a triangulated approach in which at least two reviewers screened each article. Table 1 provides the following data for each study: author/date/country/quality appraisal score, aim/research question(s), sample/setting, and results/findings. Co-researchers collaborated in the thematic analysis and synthesis of the data. The lead researcher categorized the data for each aim (i.e. engagement practices, outcomes, and associated worlds of health care) and then collaborated with co-researchers to group data into similar relationship patterns and themes. Theoretical frameworks (i.e. PFCC and Three World View) guided the thematic analysis and synthesis processes.

\section{Results}

\section{Study Characteristics}

The initial search identified 6743 articles, 6721 did not meet the review criteria (Fig. 1), and 22 articles were admitted into this review (Table 1). A few of the reasons for article exclusion were irrelevance (e.g. lack of family engagement), wrong setting (e.g. hospital), and wrong population (e.g. patients under age 65). All included articles were published in peer reviewed journals. The earliest article was published in 1988 and most recent in 2018. Study methodologies included quantitative $(n=12)$, qualitative $(n=5)$, and mixed methods $(n=5)$. Four studies were hypothetically based using case vignettes, rather than patient observations, which allowed for better understanding of provider preferences and ideal decision-making processes (Cheok et al., 
Fig. 1 PRISMA flow diagram (Moher et al., 2009)

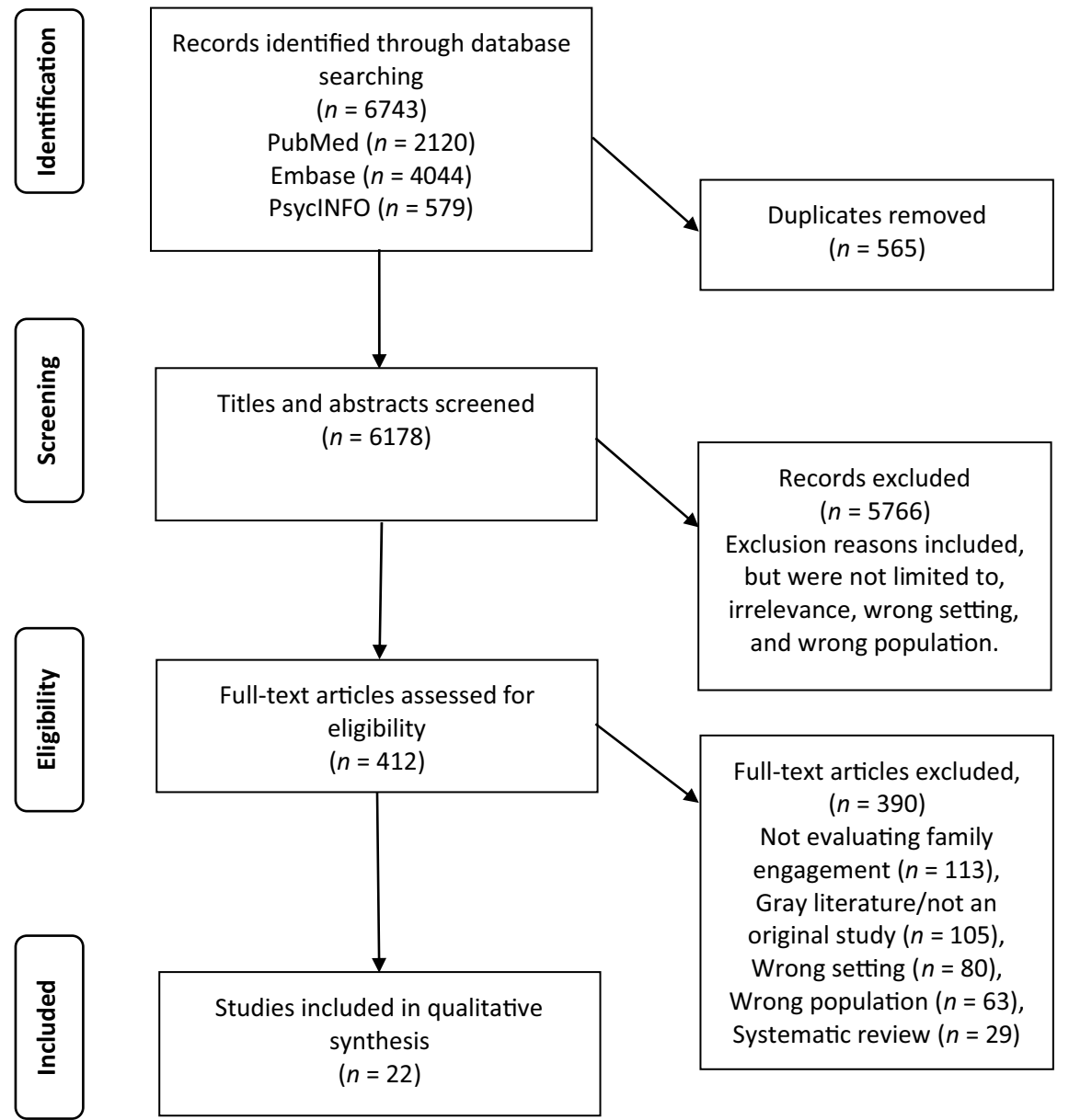

Note. PRISMA flow diagram (Moher et al., 2009).
1997; Fortinsky et al., 1995; Werner, 2006; Werner et al., 2004).

Most of the admitted studies were classified as taking place in general primary care contexts $(n=18)$, while four were specific to family medicine. Of the clinics identified as general primary care, two of them were also classified as geriatric practices. None were classified as internal medicine. Four studies were specific to Veteran's Affairs (VA; Belmin et al., 2012; D’Souza et al., 2015; Judge et al., 2011; Nichols et al., 2011). The training and education of provider participants varied widely (shown in Table 1).

Studies included perspectives of families, patients, and providers to assess outcomes of family engagement practices. Interestingly, half of the studies $(n=11)$ included family member participants and perspectives. Five included family perspectives only, three included family and patient perspectives, and three evaluated family, patient, and provider perspectives. Nine studies evaluated provider only perspectives, and none considered patient only perspectives. Both national $(n=13)$ and international $(n=9)$ studies were included, with a total of 8 nations represented in the review. Thirteen studies were conducted in at least eleven states within the United States. The United Kingdom and Israel were both represented in two studies each, while Canada, Japan, Germany, Belgium, and Australia were each represented in one study.

The terminology and definitions of families varied extensively in this review. The most common terms used to refer to support persons were "family" $(n=8)$ and "caregiver" ( $n=7)$, or some variation of these two terms (e.g. relative, family companion, informal caregiver, family caregiver, hired caregiver, carer, lay carer, family carer). Note that nearly all articles used more than one term to denote support persons (e.g. article used both "family" and "caregiver"). In most cases, studies included clear definitions of family (e.g. partner/spouse, adult children). Other terms such as "loved ones," "friend," "proxy," and "other informant," were also used to describe support persons engaged in patient care. Additionally, only one study (Vick et al., 2018) noted that more than one family member was engaged in the patient's care and participated in the study. 


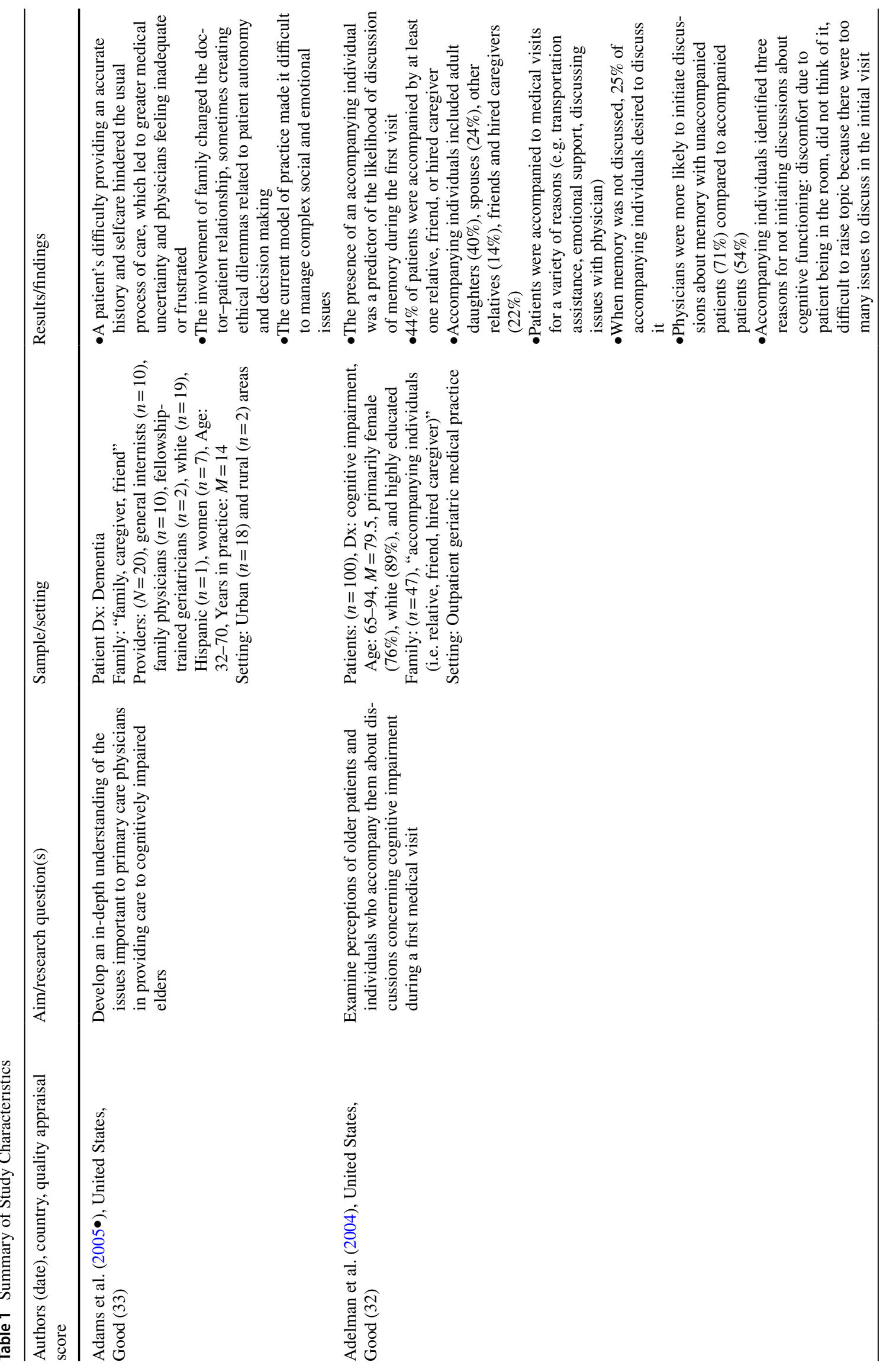




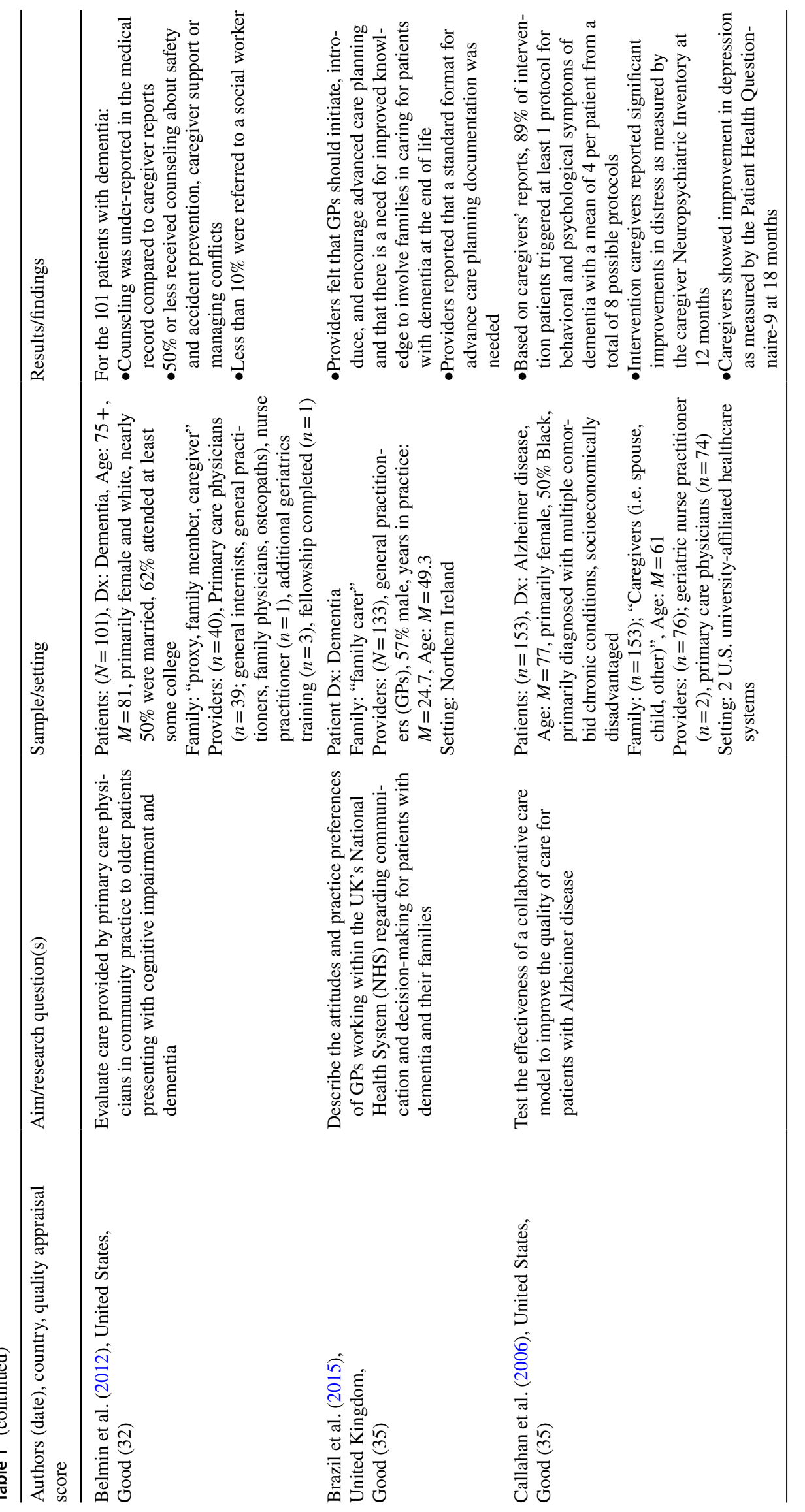




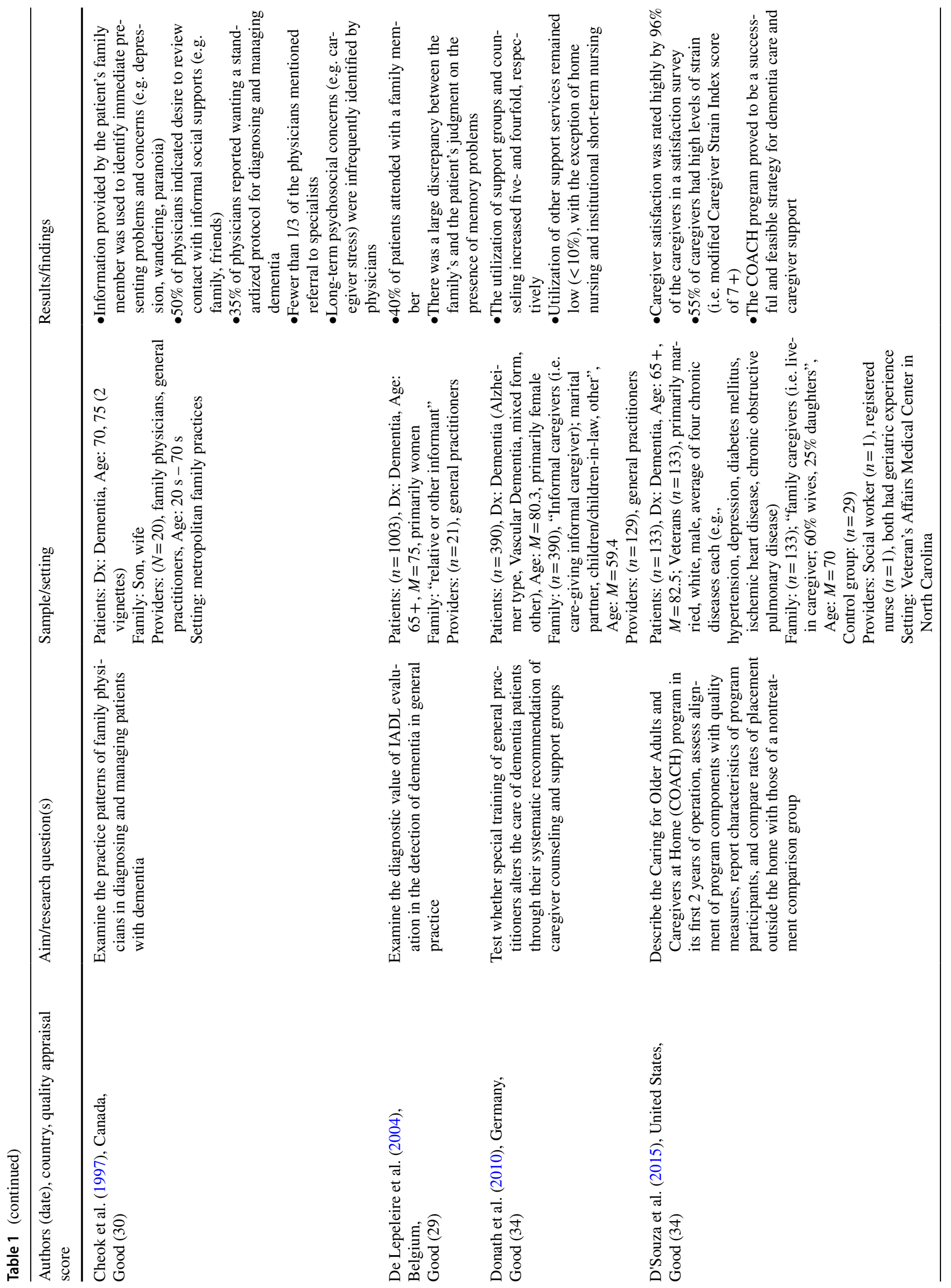




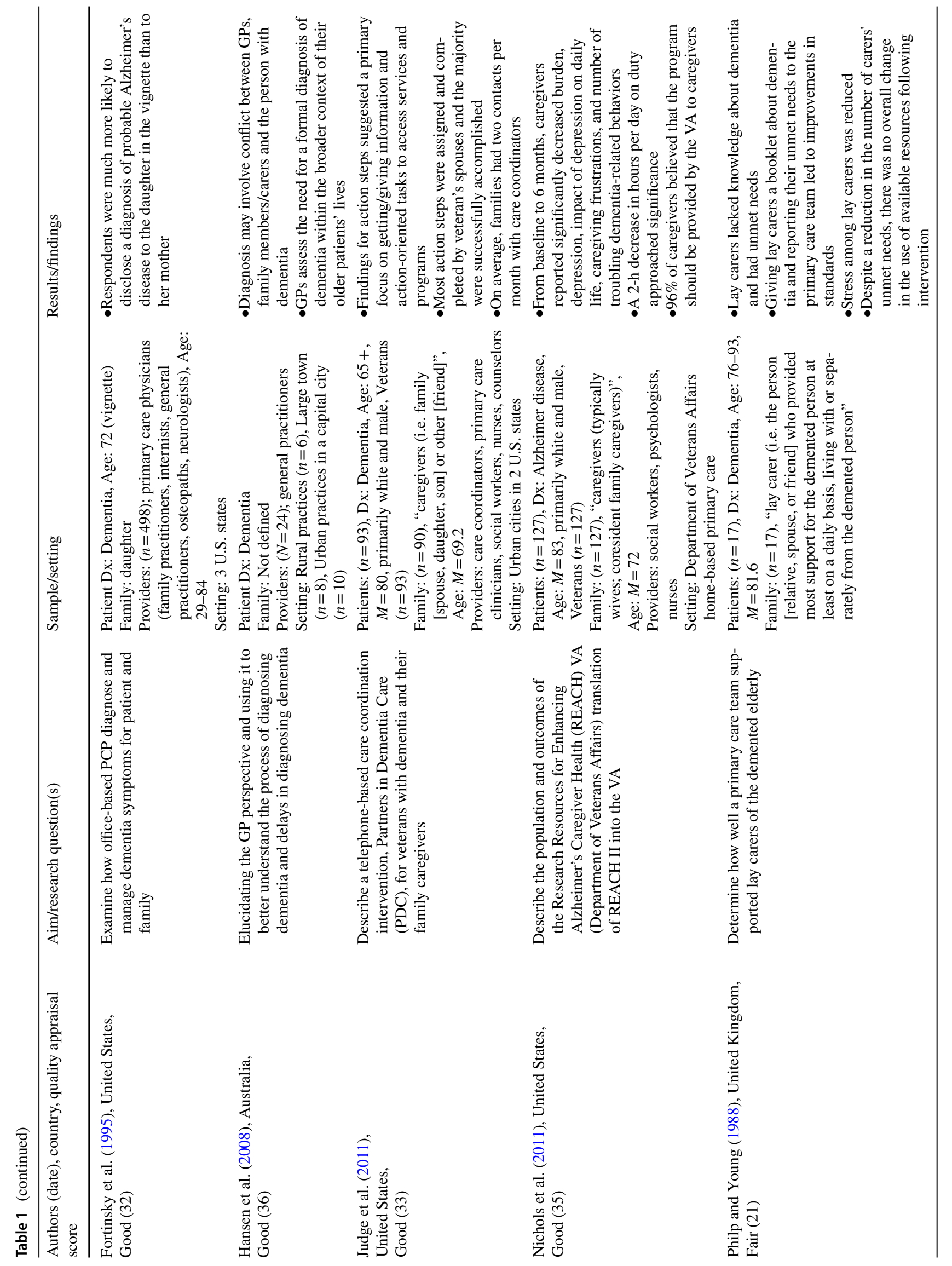




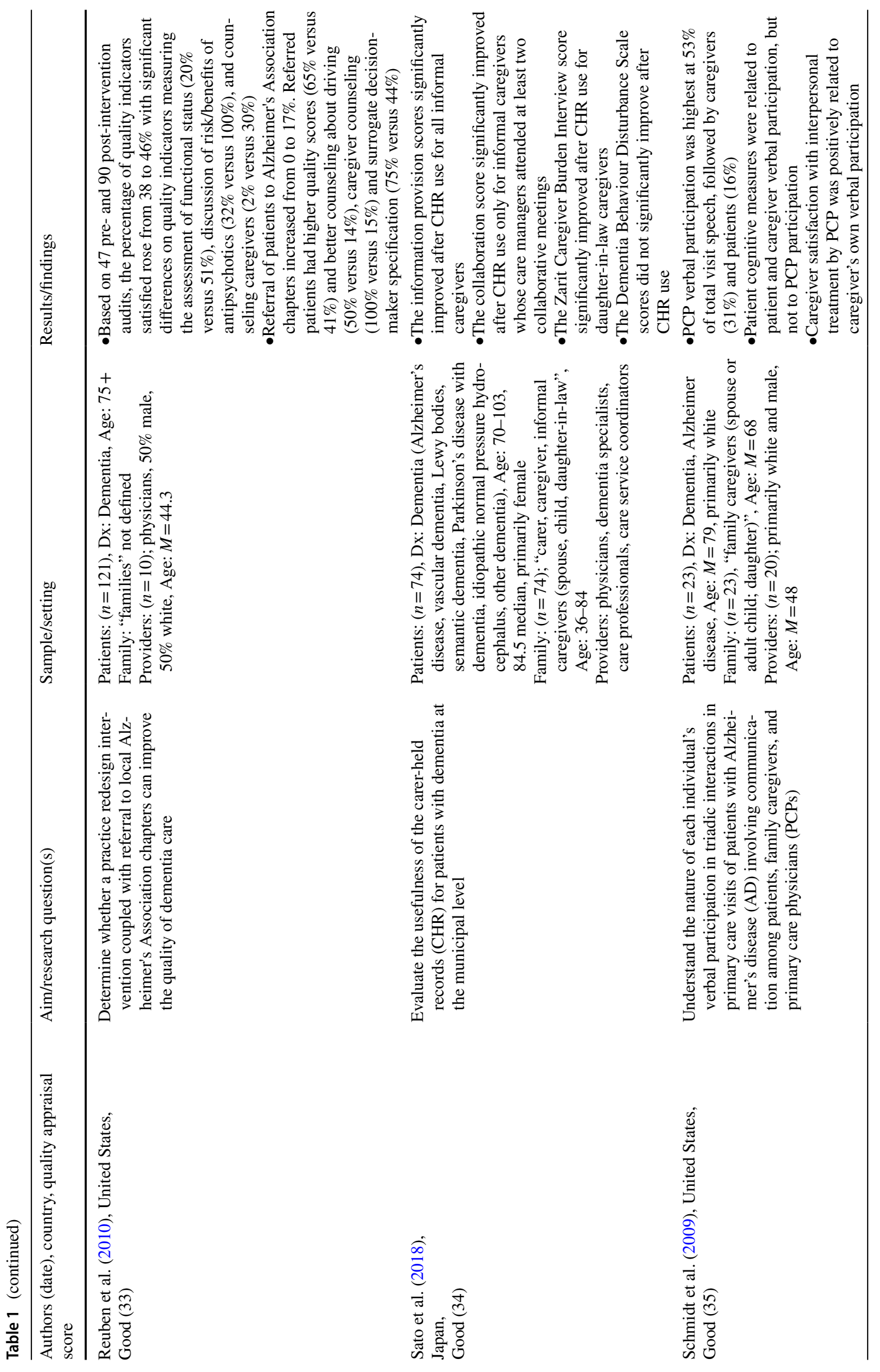




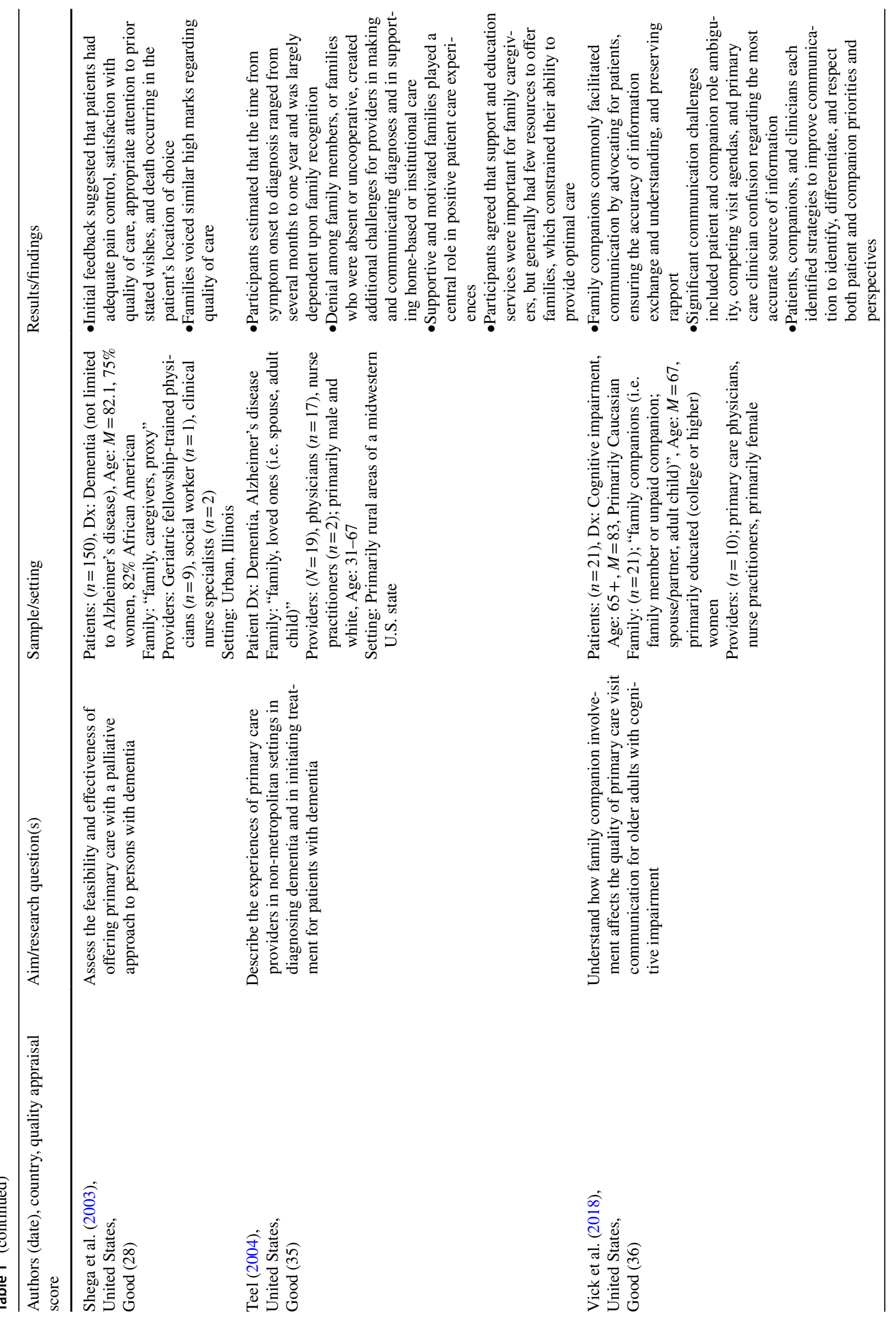




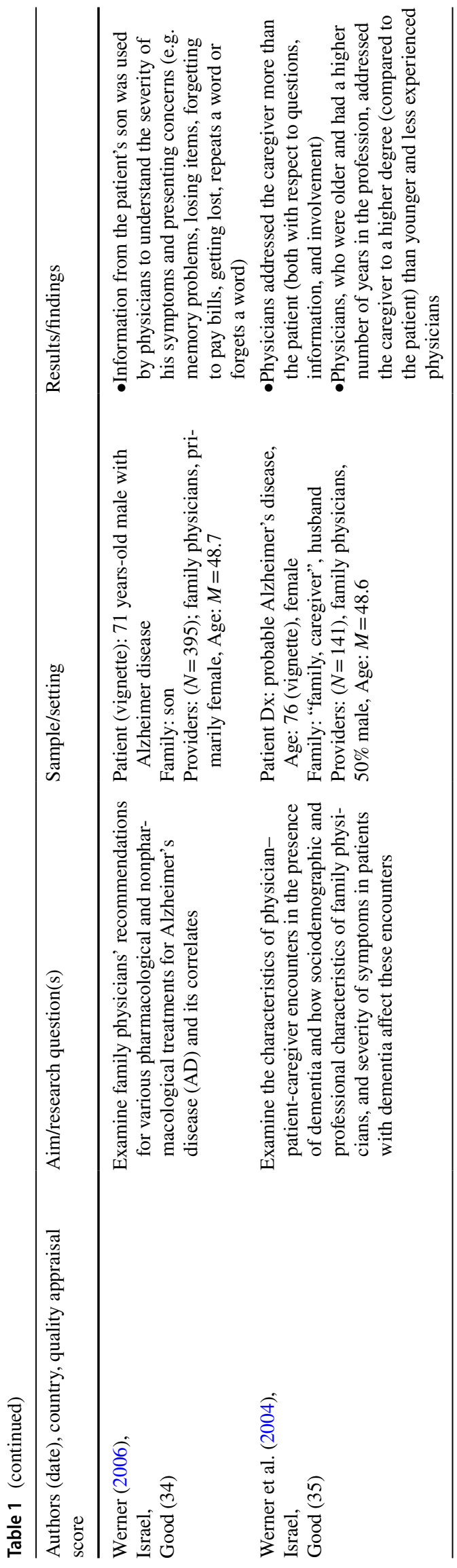

Although almost all studies incorporated demographic characteristics of the studies' samples (e.g. race/ethnicity, rural/urban, age, gender, education), only two studies included explicit conversations regarding the influence of social locations on the studies' findings (Schmidt et al., 2009; Werner et al., 2004). However, in both cases, discussions focused on (a) age, gender, and educational background differences of providers or (b) gender differences of caregivers. Explicit discussion of race and ethnicity variances were missing as were discussions of the social locations of patients regardless of the sample demographics.

This review's results were organized according to its primary aims: (a) identification of family engagement practices in primary care with older adults exhibiting CI, (b) examination of the outcomes of family engagement, and (c) organization and discussion of findings using Peek's Three World View. Then, using the theoretical frameworks (i.e. PFCC and Three World View) as a guide, researchers combed through extracted data and identified patterns and themes within each aim.

\section{Aim 1: Identify the Family Engagement Practices of PFCC in Primary Care with Older Adults Exhibiting Cl}

Identification of family engagement practices was challenging given the various levels of specificity of the included studies. However, three themes emerged involving types and methods of PFCC and family engagement: (a) empowering and supporting patients and family caregivers, (b) gathering information about the patient for diagnostic and treatment purposes, and (c) standardizing and improving communication through implementation of care coordination/management programs.

\section{Empowering and Supporting Patients and Family Caregivers}

The most robust theme emerged from 20 studies. It involved practices designed to empower and support patients and their caregivers. These studies focused on improving caregivers' emotional well-being through family counseling $(n=2$; Callahan et al., 2006; Donath et al., 2010) and support groups ( $n=8$; Adams et al., 2005; Belmin et al., 2012; Callahan et al., 2006; Donath et al., 2010; D'Souza et al., 2015; Nichols et al., 2011; Teel, 2004; Werner, 2006). This also included engaging family members who accompanied patients to medical visits by including them in goal setting and treatment planning ( $n=6$; Adams et al., 2005; Brazil et al., 2015; Hansen et al., 2008; Judge et al., 2011; Teel, 2004; Werner et al., 2004), decision making ( $n=2$; Adams et al., 2005; Brazil et al., 2015), and advanced care planning ( $n=2$; Belmin et al., 2012; Shega et al., 2003). For 
example, Judge et al. (2011) described a care coordination intervention in which care coordinators provided diseaserelated education and information, offered emotional support and coaching, connected families to local resources, and assisted with the assembly of an informal care network. The intervention was conducted using a protocol consisting of a care needs assessment, goal development, action plan, and ongoing oversight of the care coordination process. The care coordinators empowered patients and families through advising and coaching to promote successful care management. Ten studies also noted the value of healthcare team members providing caregivers with helpful information including education regarding patient's medical condition and caregiving (Belmin et al., 2012; Brazil et al., 2015; Callahan et al., 2006; Judge et al., 2011; Nichols et al., 2011; Philp \& Young, 1988; Reuben et al., 2010; Sato et al., 2018; Shega et al., 2003; Teel, 2004).

\section{Information Gathering}

The second theme involved practices from 12 studies that routinely obtained information about the patient's condition from family members. This was primarily done when caregivers accompanied patients to medical visits. Studies focused heavily on the way in which providers gathered information about the patient from the family when present in routine healthcare visits ( $n=9$; Adelman et al., 2004; Cheok et al., 1997; Fortinsky et al., 1995; Hansen et al., 2008; Sato et al., 2018; Schmidt et al., 2009; Vick et al., 2018; Werner, 2006; Werner et al., 2004). For example, providers would listen to family members' concerns about patients exhibiting memory problems. Few studies focused on how to gain this information outside of the visit, such as through telephone visits ( $n=2$; D'Souza et al., 2015; Judge et al., 2011) or the utilization of a caregiver notebook $(n=1$; Nichols et al., 2011).

\section{Standardized and Improved Communication}

Finally, the third theme emerged in 14 studies. It entailed practices by which healthcare teams standardized and/or improved communication between patients, families, providers, and others involved in their care. Few studies included training providers and healthcare team members on how to care for and engage families ( $n=3$; Donath et al., 2010; Reuben et al., 2010; Sato et al., 2018), yet this was identified as a need in more than $36 \%$ of the studies reviewed $(n=8$; Adams et al., 2005; Adelman et al., 2004; Brazil et al., 2015; Cheok et al., 1997; Donath et al., 2010; Fortinsky et al., 1995; Hansen et al., 2008; Teel, 2004). Six studies examined care coordination and collaborative care management as a way to employ PFCC (Callahan et al., 2006; D'Souza et al., 2015; Donath et al., 2010; Judge et al., 2011; Sato et al.,
2018; Shega et al., 2003). Two studies included information from care management programs in the electronic medical records (EMR) and required the physician to co-sign notes, ensuring that they would be aware of family information such as goals and concerns (Judge et al., 2011; D'Souza, 2015). It is worth noting that none of the included studies used the EMR to facilitate communication between family members and the healthcare team.

\section{Aim 2: Examine the Outcomes of PFCC}

Outcomes of family engagement practices were clustered by the review researchers into favorable, neutral, and unfavorable themes, and then sorted into subthemes. Favorable outcomes included findings that described family engagement as providing some value or benefit to the patient, family, or healthcare system, while unfavorable outcomes included findings that could be perceived as problematic or negative. Neutral outcomes included observations that were neither beneficial nor problematic, but noteworthy for PFCC implementation and/or research. Co-researchers collaborated to cluster each theme and subtheme as described below. Outcomes of PFCC were elucidated from multiple perspectives (i.e. patient, family, provider) and are discussed in each theme.

\section{Favorable PFCC Outcomes}

Benefits to Patients Five studies indicated multiple benefits of engaging families in the care of patients for the patients themselves. These benefits included reduction of problematic behaviors (Callahan et al., 2006), improved safety at home (Nichols et al., 2011), increased satisfaction with care (Adams et al., 2005; Shega et al., 2003), improved psychosocial symptoms (Callahan et al., 2006), and assisted in identifying goals for care (Judge et al., 2011). It is important to note that none of the included studies measured benefit to patients in the same way.

Benefits to Family Benefits of PFCC to family members were measured in 13 studies. Family engagement was shown to reduce caregiver stress (Callahan et al., 2006; Nichols et al., 2011; Philp \& Young, 1988; Sato et al., 2018), increase service utilization of support groups and family counseling (Callahan et al., 2006; D'Souza et al., 2015; Donath et al., 2010; Nichols et al., 2011), and increase satisfaction with care (D'Souza et al., 2015; Schmidt et al., 2009; Shega et al., 2003; Vick et al., 2018). A common way of measuring family member benefit was through education about CI and its influence on patients and families. Family education led to better understanding and knowledge of CI that enabled caregivers to provide better care to patients (Brazil et al., 2015; Hansen et al., 2008; Nichols et al., 2011; 
Teel, 2004; Vick et al., 2018) and reduced the number of unmet needs (Judge et al., 2011; Philp \& Young, 1988). Caregivers reported feeling more supported (Hansen et al., 2008; Philp \& Young, 1988), and prepared (Brazil et al., 2015). Family engagement practices also benefited families by helping them to identify care goals (Judge et al., 2011) and led to increased caregiver satisfaction of the provider's treatment of the patient (Schmidt et al., 2009). While one study noted that caregivers found it helpful to utilize alternative forms of communication with providers (e.g. communicating through the EMR; Vick et al., 2018), none of the studies evaluated such practices.

Benefits to Healthcare Providers and Health Systems A wide variety of outcomes related to healthcare providers and organizations were included in 10 studies. Providers frequently discussed the benefits of having additional information from family members during the diagnostic process (Hansen et al., 2008; Teel, 2004; Vick et al., 2018). Providers also highlighted viewing the family as essential to optimal care, particularly when diagnosed with a CI (Adams et al., 2005; Donath et al., 2010; Teel, 2004). Additionally, providers noted benefits when families were engaged as evidenced by having "successful" cases (Teel, 2004), preserving rapport with patients (Vick et al., 2018), and saving time in care visits (e.g. not having to repeat instructions; Nichols et al., 2011). Five studies evaluated PFCC by considering (a) improved collaboration (Sato et al., 2018), (b) feasibility of implementation (Judge et al., 2011), (c) alignment with quality measures (D'Souza et al., 2015), (d) higher resource utilization rates (Donath et al., 2010; Shega et al., 2003), and (e) providers' increased conformity to drug therapy guidelines (Donath et al., 2010). Convenience of electronic communication was mentioned by providers (Vick et al., 2018), but not evaluated. Similarly, neither was cost savings (e.g. reduced hospital and emergency room admissions, along with decreased use of expensive technologies; Shega et al., 2003).

\section{Neutral PFCC Observations}

Communication Patterns with Engaged Families The influence of PFCC on communication patterns between providers, patients, and family members, was one of the most common observations made in the studies reviewed. Researchers measured communication within care visits, such as (a) talking time (Schmidt et al., 2009), (b) initiation of conversations about CI symptoms and concerns (Adelman et al., 2004; Brazil et al., 2015), and (c) revealing of a CI diagnosis (Belmin et al., 2012; Fortinsky et al., 1995; Hansen et al., 2008; Teel, 2004). Communication outside of the visit was also studied (e.g. frequency of communication did not increase [Judge et al., (2011)]; means of communi- cation included written notes, speaking on the phone, and using a secure patient portal for electronic messaging in the EMR [Vick et al., 2018]).

At least three studies evaluated potential barriers to communication between providers and patients and/or families (e.g. providers not wanting to increase unnecessary anxiety in patients and family members [Donath et al., 2010]; family not wanting to discuss concerns with/without patient present [Adelman et al., 2004]; providers avoiding the conversation due to stigma [Teel, 2004]; greater geographical distance between patients and family members [Teel, 2004]). While few noted differences in communication styles between providers caring for patients with $\mathrm{CI}$ (e.g. internists and family physicians were more likely to engage in extensive discussions about dementia symptom management with patients and family members compared to osteopaths and general practitioners [Fortinsky et al., 1995], physicians with more years of experience would interact less with patients and families [Werner et al., 2004]; male providers were more likely to inform patients of a CI diagnosis than female providers [Werner et al., 2004]), none examined in detail why such differences emerged.

The means of communication between healthcare team members were rarely examined (e.g. co-signing notes in EMR [D'Souza et al., 2015]; use of carer-held records [CHR; Sato et al., 2018]). The CHR were used to provide information about the patient's condition and improve collaboration between caregivers and healthcare teams (Sato et al., 2018). Furthermore, studies noted the importance of providers' communication skills and the critical need for developing these skills to effectively communicate with families (e.g. listening is better than an assessment tool [Teel, 2004]). However little attention was given to provider training and how these skills are developed. Additionally, Cheok et al. (1997) found that providers need more information about community resources and training for how to explain benefits of the resources to the family.

Preparing Multidisciplinary Teams to Engage Families While a variety of professionals were included in these studies (e.g. care coordinators [Judge et al., 2011], nurse coordinators [Shega et al., 2003], counselors and family therapists [Donath et al., 2010; D'Souza et al., 2015; Judge et al., 2011; Werner et al., 2006], social workers [Belmin et al., 2012; D'Souza et al., 2015; Judge et al., 2011; Nichols et al., 2011; Shega et al., 2003]), the extent of collaboration between the professionals during family engagement varied widely. This makes it difficult to evaluate similarities or differences of multidisciplinary teams. Furthermore, medical providers identified the need for more training and standardization of PFCC at various stages of caring for a patient with CI (e.g. diagnosis and management [Brazil et al., 2015], end of life [Adams et al., 2005]). 
Provider Decision-Making with Engaged Families Four studies investigated what providers used to determine their next steps in caring for a patient with CI (e.g. prescription of medications; referral to specialist). Their responses varied according to patient level of CI severity (Cheok et al., 1997; Fortinsky et al., 1995; Werner, 2006; Werner et al., 2004). However, none described how family engagement, or collaboration with other specialists, was used during the diagnostic process or treatment plan formulation. Of note, this theme was included as a neutral observation given that it does not describe a negative outcome. The lack of describing family engagement did not present a negative outcome of family engagement practices. Rather, this finding is an observation of a gap within the literature and further research is needed to contribute to the understanding of providers' decision-making processes when engaging families.

Resource Underutilization Finally, multiple studies noted that despite PFCC, family members underutilized resources available to them. Providers voiced desire and value for resources in their communities (Cheok et al., 1997), but complained that resources are often unavailable or underutilized (Philp \& Young, 1988; Teel, 2004). Reasons for lack of resource use included (a) lack of understanding (Shega et al., 2003), (b) inconvenience (Sato et al., 2018), and (c) geographical restrictions (e.g. adult children living in different states; Teel, 2004). However, while studies captured the presence of these challenges, recommendations for implementing/improving PFCC are omitted.

\section{Unfavorable PFCC Outcomes}

Restricted Patient Agency In two studies (Adams et al., 2005; Vick et al., 2018), providers and families expressed concerns about the focus of the medical visit turning from the patient to the family member and the ethical concerns that result (e.g. patient autonomy, decision making). Providers and caregivers both worried that increased engagement of the family member in the patient's care could lead to leaving the patient out (Adams et al., 2005) or the patient no longer being the primary focus of the visit (Vick et al., 2018). A third study (Werner et al., 2004) confirmed that providers do at times speak to family more than patients (e.g. older, more experienced physicians addressed caregivers more than patients when compared to younger, less experienced physicians). This led to a concern about conflict becoming an issue when engaging families. Conflicts could arise from differing goals or priorities for care between providers, family, and/or patients (Vick et al., 2018). Moreover, providers reported that families could be manipulative (Hansen et al., 2008) or unrealistic (Teel, 2004), which can impede care.
Documentation Inconsistencies Belmin et al. (2012) found that the lack of addressing CI symptoms by providers and patients in care visits resulted in patients not receiving care that could help to reverse or improve symptoms. However, few studies acknowledged the cause of not addressing CI directly (e.g. stigma associated with CI; Teel, 2004). Furthermore, the documentation of how providers, patients, and families addressed $\mathrm{CI}$ in care visits was also inconsistent. What family members and patients reported happening in care visits differed from what providers documented in the EMR (Belmin et al., 2012). The study found that family members often reported more happening in the visit than what providers noted in the EMR. This is important to know for future research aiming to evaluate family engagement using EMR data. This review highlighted the stark void in current literature regarding EMR use and family engagement with this population.

\section{Aim 3: Organize Findings According to Peek's Three World View}

Researchers organized outcomes and implications of PFCC from the review according to the Three World View (Peek, 2008; see Table 2). Clinical, operational, and financial outcomes, as well as training/educational implications of studies admitted into the review are discussed. Overall, all studies $(N=22)$ addressed clinical outcomes of family engagement.

\section{Clinical Outcomes}

All studies $(N=22)$ included in this review reported clinical implications of PFCC and family engagement. Patient health outcomes included (a) reduced memory and behavior problems (Callahan et al., 2006; Shega et al., 2003), (b) improved detection of cognitive status (De Lepeleire et al., 2004), (c) increased patient satisfaction with PCP and care (Schmidt et al., 2009), (d) improved assessment of activities of daily living (ADL; Shega et al., 2003) and instrumental activities of daily living (IADL; Shega et al., 2003), (e) decreased perceived pain (evaluated by caregivers; Shega et al., 2003), (f) fewer bothersome patient symptoms (evaluated by caregivers; Shega et al., 2003), (g) improved quality of care (Shega et al., 2003), and (h) increased likelihood of patients dying in their desired location (Shega et al., 2003). These outcomes were mainly studied from the perspectives of caregivers and providers and not the perspectives of patients. Both providers and family members expressed concerns about diminishing the patient's agency through their communication, but none of these studies evaluated the patient's perspective on engaging family members in healthcare visits.

Studies also evaluated caregivers' health and wellbeing, primarily from their perspective. Most discussed what 
Table 2 Example Themes and Studies Addressed Within Each of the Four Worlds of Health Care

\begin{tabular}{|c|c|c|}
\hline World of health care & $\begin{array}{l}\text { Number of studies } \\
\text { addressing this } \\
\text { world }\end{array}$ & Example themes and studies \\
\hline Clinical & 22 & $\begin{array}{l}\text { Patient health outcomes: } \\
\text { - Reduced memory and behavior problems (Callahan et al., 2006; Shega et al., 2003) } \\
\text {-Improved detection of cognitive status (De Lepeleire et al., 2004) } \\
\text {-Increased patient satisfaction with PCP and care (Schmidt et al., 2009) } \\
\text { Caregiver health outcomes: } \\
\text {-Improved mood (e.g. reduced depression (Callahan et al., 2006; Judge et al., 2011; Shega et al., } \\
\text { 2003) } \\
\text {-Lessened relationship strain between patient and caregiver (Judge et al., 2011) } \\
\text { - Reduced caregiver stress (Callahan et al., 2006; Philp \& Young, 1988) }\end{array}$ \\
\hline Operational & 14 & $\begin{array}{l}\text { - Family engagement did not have a negative impact on provider workflow (e.g. increase the fre- } \\
\text { quency of phone calls to the healthcare team; Judge et al., 2011) } \\
\text {-Usefulness of communication within the EMR (Vick et al., 2018) } \\
\text {-Providers co-signed notes of other team members in the EMR (D'Souza et al., 2015; Sato et al., } \\
\text { 2018) }\end{array}$ \\
\hline Financial & 4 & $\begin{array}{l}\text {-Decreased hospital admissions and reduced expenses related to life sustaining technologies (e.g. } \\
\text { feeding tubes; Shega et al., 2003) } \\
\text {-Decreased cost of time spent on caregiving (Nichols et al., 2011) } \\
\text { - No change in time to nursing facility placement and related expenses (Callahan et al., 2006) } \\
\text {-Avoidance of unnecessary testing expenses (Fortinsky et al., 1995) }\end{array}$ \\
\hline Educational & 9 & $\begin{array}{l}\text { - Training on benefits of resources in early stages of dementia helped to improve PCP consistency in } \\
\text { referrals to resources (Reuben et al., 2010) } \\
\text { - Trainings for communication skills would improve providers' ability to effectively engage families } \\
\text { (Vick et al., 2018) while simultaneously trying to include patients with CI (Schmidt et al., 2009) }\end{array}$ \\
\hline
\end{tabular}

Studies may be included in more than one category (e.g. a study may address both the clinical and educational worlds)

happened in care visits and what healthcare teams did to support them. Caregiver health outcomes as a result of PFCC included (a) improved mood (e.g. reduced depression [Callahan et al., 2006; Judge et al., 2011; Shega et al., 2003]), (b) lessened relationship strain (Judge et al., 2011), (c) reduced stress (Callahan et al., 2006; Philp \& Young, 1988), (d) minimized patient's behavior disturbance and reduced caregiver burden (Sato et al., 2018), (e) decreased caregiver strain (Shega et al., 2003), and (f) increased caregiver satisfaction with PCP and care (Schmidt et al., 2009). It is important to note that none of the studies evaluated provider health and wellbeing outcomes (e.g. provider turnover, compassion fatigue) or relational outcomes.

\section{Operational Outcomes}

Fourteen studies examined operational outcomes. These included (a) improved provider workflow, (b) increased utilization of community resources, (c) collaborative documentation in the patient's medical record, and (d) varying levels of collaboration between healthcare team members. Providers noted that family members did not have a negative impact on provider workflow. For example, family members did not increase the frequency of phone calls to the healthcare team as expected in one study (Judge et al., 2011). Another study noted the useful nature of using the EMR to communicate but did not provide specifics about how this happens operationally (Vick et al., 2018). Two studies engaged the providers by having them co-sign notes of other team members in the EMR (D'Souza et al., 2015; Sato et al., 2018). However, it is unclear how often or to what extent the providers utilized the available information and how it impacted patient care. Similarly, while collaboration among multidisciplinary healthcare team members was found helpful (e.g. addition of a nurse coordinator viewed as essential to success of program; Shega et al., 2003), the level of collaboration was not evaluated.

\section{Financial Outcomes}

Four studies discussed possible financial benefits of PFCC, such as decreased hospital admissions and reduced expenses related to life sustaining technologies (e.g. feeding tubes; Shega et al., 2003). However, none of them included an actual financial analysis or examined the financial impacts of engaging families. Rather, studies noted outcomes of PFCC such as (a) decreased cost of time spent on caregiving (Nichols et al., 2011), (b) increased cost of time spent in visits (Adelman et al., 2004), (c) no change in time to nursing facility placement and related expenses (Callahan et al., 2006), (d) avoidance of unnecessary testing expenses 
(Fortinsky et al., 1995), and (e) reductions in hospitalization rates and associated costs (Callahan et al., 2006).

\section{Educational Implications}

Nine of the articles in this review included a discussion of training and educational opportunities for providers to learn more about the value of PFCC when treating CI. For example, in one study researchers observed that PCPs were not referring early-stage dementia patients to a beneficial resource when they encountered patient and/or family reluctance (Reuben et al., 2010). A special meeting was held to discuss how PCPs could better present and discuss the value of the early referral with patients and their families. The researchers found that this additional training opportunity helped to improve consistency in early-stage referrals. Furthermore, researchers indicated trainings in communication skills would help to improve providers' ability to effectively engage families (Vick et al., 2018) while simultaneously making an effort to include patients with CI (Schmidt et al., 2009). Most studies acknowledged the need for additional training, direction, and support as it was a new skill as well as research on training outcomes related to family engagement and patient outcomes. To date, it is unclear what the best method is for training multidisciplinary teams to work together using PFCC and maintaining fidelity of the method practiced.

\section{Discussion}

The purpose of this study was to better understand the outcomes of engaging families in primary care settings when caring for patients with CI. Despite the usefulness of the results in the included studies, the authors were surprised to find that none of the studies explicitly explored the direct outcomes of engaging family in the care of older adults with CI (i.e. compared care with family engagement to care without family engagement). Nor did any of the studies explore the role of family engagement practices from the patient's perspective. These are areas that should be explored in future research. Regardless, utilizing PFCC (Johnson \& Abraham, 2012) and Three World View (Peek, 2008), this systematic review provides Medical Family Therapists, healthcare administrators, policy makers, educators, and clinicians with information related to family engagement and how it can be implemented and enhanced in the care of patients with CI.

\section{Implications of Family Engagement Practices}

Special attention should be paid to studying successful methods of balancing family involvement and maintaining patient autonomy (Jazieh et al., 2018). Medical family therapists may help to promote patient agency through the engagement of families in a manner that does not diminish the patient's autonomy (Hodgson et al., 2014; McDaniel et al., 2014a; Mendenhall et al., 2018). This might include speaking directly to patients during the primary care visit rather than speaking about patients to their family members accompanying them to the visit. It may also involve elucidating and valuing a patient's decision-making capacity even when the patient disagrees with their family and/or PCP. It would be beneficial for future research to explore how family engagement practices influence the autonomy and agency of the patient from patients' perspectives as this was missing from the studies included in this review. Furthermore, providers should have flexibility and training on the various methods of engagement (e.g. EMR, videoconferencing) since involved family members may not be able to attend medical visits with the patient due to geographical distance (Teel, 2004). Medical family therapists are oftentimes well positioned to offer training in how to engage families in healthcare visits, particularly in allied health, medical school, and residency education settings (Hodgson et al., 2014; Mendenhall et al., 2018).

\section{Implications of PFCC Outcomes}

PFCC has the potential to reduce barriers for family engagement in CI patient visits by engaging families through means beyond accompanying patients to healthcare visits (e.g. phone visits [D'Souza et al., 2015; Judge et al., 2011]; electronic communication [Vick et al., 2018]). However, greater knowledge and understanding of barriers requires more consistent and accurate documentation of efforts in the EMR (Belmin et al., 2012). This review found no research on how the EMR could be useful in primary care settings to improve and increase family engagement. A recent study revealed that EMR data collected during routine patient care (e.g. medical notes containing information from family) may help to identify dementia within one year of symptom onset (Miled et al., 2020) but nothing is known about what role family engagement plays in expediting or delaying this process. Research is needed on how the method of family engagement in the care of patients with CI influences the diagnosis and care experience and what methods are most beneficial for patients, families, and healthcare teams.

\section{Clinical, Operational, Financial, and Educational Implications}

This review also revealed no standard practice or procedures for incorporating information obtained from family members about the patient's condition into the care of patients with CI. There is also a lack of research on clinical, operational, financial, and training/educational benefits of implementing 
family engagement practices. Providers often rely on families to initiate conversations about cognitive concerns (Nicosia et al., 2019) but how both parties prefer to exchange information efficiently and effectively should be examined.

Research is needed to understand how differences in social locations (e.g. race/ethnicity, gender, age) influence clinical outcomes. Studies in this review included information regarding participant characteristics, but rarely were the influences of those characteristics analyzed or discussed. Except for one study (Schmidt et al., 2009), differences in caregiver and patient genders were not discussed. Callahan et al. (2006) and Shega et al. (2003) both made note that patients were mostly Black and African American, but how that influenced their care and experience was not evaluated. Additionally, provider descriptors for these studies were not included to assess for variations in outcomes when providers and patients are of similar or dissimilar race and ethnicity.

This review also identified provider education as a barrier to effectively engaging families in caring for patients with CI. Studies showed that providers experienced varying degrees of comfort and confidence when communicating with and engaging families. However, all studies, apart from one (Sato et al., 2018), most often referred to physician-only education and did not recognize the presence and role of multidisciplinary and integrated care teams. Patients with CI have high health care utilization rates, and most are cared for by a variety of healthcare specialists (Lugo-Palacios \& Gannon, 2017). Medical family therapists could add to the body of literature through examination of how family engagement is addressed within inter-professional education so that multidisciplinary healthcare teams are prepared to effectively implement PFCC.

\section{Limitations}

A limitation of this systematic review is the omission of gray literature given that it may have relevancy to PFCC as an understudied field. However, this was done to ensure a high level of quality of included studies given the rigorous peer-review process. Another potential limitation may be the lack of consistency when defining and interpreting "family" in the included studies as this may present challenges when developing strategies for engaging support persons in the patient's care. Additionally, the inclusion of findings from multiple countries may present challenges to generalizability given global variations in healthcare systems. However, expanding the research frame to be more inclusive is important to being able to better examine differences and similarities of family engagement across countries and social locations. Given that the analysis of the influence of patients' race and gender on PFCC practices and outcomes were omitted from the reviewed articles, discussion of such influences of identities between and among patients, families, and healthcare team members was limited in this manuscript.

\section{Conclusion}

Medical family therapists are poised to apply and expand the findings from this systematic review. Results identify favorable outcomes of engaging families in primary care for patients with CI. Engaging families by including them in primary care visits, providing families with education, and encouraging resource utilization, resulted in improved satisfaction with patient care (Adams et al., 2005; Shega et al., 2003) and reduced caregiver stress (Callahan et al., 2006; Nichols et al., 2011; Philp \& Young, 1988; Sato et al., 2018). However, application of family engagement practices remains inconsistent and ambiguous across settings. While primary healthcare teams often interact with family members of patients with CI, the active, intentional, and effective engagement of those families is not yet standard practice. This review also identified potential negative outcomes of family engagement including restricted patient agency and inconsistent documentation within the EMR. Medical family therapists may help alleviate these challenges by promoting agency and communion (McDaniel et al., 1992) when engaging patients with $\mathrm{CI}$ and their families. Furthermore, additional training and attention to the implementation of family engagement practices may help to reduce inconsistencies within EMR systems. The field of Medical Family Therapy has an opportunity to advance the implementation of PFCC and family engagement with older adults exhibiting $\mathrm{CI}$ in primary care settings through influential research, policy development, and training of PCPs through a familycentered approach.

Funding The authors received no financial support for the research, authorship, and/or publication of this article.

\section{Declarations}

Conflict of interest The authors declared no potential conflicts of interest with respect to the research, authorship, and/or publication of this article.

\section{References}

References marked with $\bullet$ indicate studies included in the systematic review

•Adams, W. L., McIlvain, H. E., Geske, J. A., \& Porter, J. L. (2005). Physicians' perspectives on caring for cognitively impaired 
elders. The Gerontologist, 45(2), 231-239. https://doi.org/10. 1093/geront/45.2.231

-Adelman, R. D., Greene, M. G., \& Friedmann, E. (2004). Discussions about cognitive impairment in first medical visits: Older patients' perceptions and preferences. American Journal of Alzheimer's Disease and Other Dementias, 19(4), 233-238. https://doi.org/10.1177/153331750401900409

Agency for Healthcare Research and Quality (2011). The patientcentered medical home: Strategies to put patients at the center of primary care. Patient-Centered Medical Home Decisionmaker Brief. https://pcmh.ahrq.gov/sites/default/files/attac hments/Strategies \%20to\%20Put\%20Patients\%20at\%20the\% 20Center\%20of\%20Primary\%20Care.pdf

Alzheimer's Association. (2009). Alzheimer's disease facts and figures. Alzheimer's \& Dementia, 5(3), 234-270. https://doi.org/ 10.1016/j.jalz.2009.03.001

Alzheimer's Association. (2014). Alzheimer's \& dementia: 2014 Alzheimer's disease facts and figures. The Journal of the Alzheimer's Association, 10(2), e47-e92. https://doi.org/10. 1016/j.jalz.2014.02.001

Alzheimer's Association (2017). Choosing a doctor to evaluate memory and thinking problems. https://www.alz.org/natio nal/documents/topicsheet_choosingdoctor.pdf

Alzheimer's Association. (2020). 2020 Alzheimer's disease facts and figures. Alzheimer's \& Dementia, 16(3), 391-460. https://doi. org/10.1002/alz.12068

American Medical Association. (2016). AMA code of medical ethics' opinions relevant to patient- and family-centered care. AMA Journal of Ethics, 18(1), 45-48. https://doi.org/10.1001/ journalofethics.2016.18.1.coet1-1601

-Belmin, J., Min, L., Roth, C., Reuben, D., \& Wenger, N. (2012). Assessment and management of patients with cognitive impairment and dementia in primary care. The Journal of Nutrition, Health \& Aging, 16(5), 462-467. https://doi.org/ 10.1007/s12603-012-0026-Z

Benzer, J. K., Beehler, S., Miller, C., Burgess, J. F., Sullivan, J. L., Mohr, D. C., Meterko, M., \& Cramer, I. E. (2012). Grounded theory of barriers and facilitators to mandated implementation of mental health care in the primary care setting. Depression Research and Treatment, 2012, 597157-597211. https://doi. org/10.1155/2012/597157

Bertakis, K. D., \& Azari, R. (2011). Patient-centered care is associated with decreased health care utilization. Journal of the American Board of Family Medicine: The Journal of the American Board of Family Medicine, 24(3), 229-239. https:// doi.org/10.3122/jabfm.2011.03.100170

Boise, L. (2006). Improving dementia care through physician education: Some challenges. Clinical Gerontologist, 29(2), 3-10. https://doi.org/10.1300/J018v29n02 02

-Brazil, K., Carter, G., Galway, K., Watson, M., \& van der Steen, Jenny T. (2015). General practitioners' perceptions on advance care planning for patients living with dementia. BMC Palliative Care, 14(1), 14-14. https://doi.org/10.1186/ s12904-015-0019-x

Bunn, F., Burn, A., Goodman, C., Robinson, L., Rait, G., Norton, S., Bennett, H., Poole, M., Schoeman, J., \& Brayne, C. (2016). Comorbidity and dementia: A mixed method study on improving health care for people with dementia (CoDem). Health Services and Delivery Research., 4(8), 1-156. https://doi.org/10.3310/ hsdr04080

-Callahan, C. M., Boustani, M. A., Unverzagt, F. W., Austrom, M. G., Damush, T. M., Perkins, A. J., Fultz, B. A., Hui, S. L., Counsell, S. R., \& Hendrie, H. C. (2006). Effectiveness of collaborative care for older adults with Alzheimer disease in primary care. Journal of the American Medical Association, 295(18), 21482157. https://doi.org/10.1001/jama.295.18.2148
Carman, K. L., Dardess, P., Maurer, M., Sofaer, S., Adams, K., Bechtel, C., \& Sweeney, J. (2013). Patient and family engagement: A framework for understanding the elements and developing interventions and policies. Health Affairs (project Hope), 32(2), 223-231. https://doi.org/10.1377/hlthaff.2012.1133

Centers for Disease Control and Prevention (CDC; 2014). Cognitive impairment: A call for action, now! https://www.cdc.gov/aging/ pdf/cognitive_impairment/cogimp_poilicy_final.pdf

•Cheok, A. S., Cohen, C. A., \& Zucchero, C. A. (1997). Diagnosing and managing dementia patients: Practice patterns of family physicians. Canadian Family Physician, 43, 477-482. https:// pubmed.ncbi.nlm.nih.gov/9116519/

Cooper, H. (2017). Research synthesis and meta-analysis: A step-bystep approach (5th ed.). Sage.

-De Lepeleire, J., Aertgeerts, B., Umbach, I., Pattyn, P., Tamsin, F., Nestor, L., \& Krekelbergh, F. (2004). The diagnostic value of IADL evaluation in the detection of dementia in general practice, Aging \& Mental Health, 8(1), 52-57 https://doi.org/10.1080/ 13607860310001613338

•Donath, C., Gräßel, E., Großfeld-Schmitz, M., Menn, P., Lauterberg, J., Wunder, S., Marx, P., Ruckdäschel, S., Mehlig, H., \& Holle, R. (2010). Effects of general practitioner training and family support services on the care of home-dwelling dementia patients-results of a controlled cluster-randomized study. BMC Health Services Research, 10(1), 314-314. https://doi.org/10.1186/ 1472-6963-10-314

•D’Souza, M. F., Davagnino, J., Hastings, N., Sloane, R., Kamholz, B., \& Twersky, J. (2015). Preliminary data from the Caring for Older Adults and Caregivers at Home $(\mathrm{COACH})$ program: A care coordination program for home-based dementia care and caregiver support in a Veterans Affairs medical center. Journal of American Geriatrics Society (JAGS), 63(6), 1203-1208. https:// doi.org/10.1111/jgs. 13448

•Fortinsky, R. H., Leighton, A., \& Wasson, J.H. (1995). Primary care physicians' diagnostic, management, and referral practices for older persons and families affected by dementia. Research on Aging, 17(2), 124-148. https://doi.org/10.1177/0164027595 172002

Garfield, R., Musumeci, M., Reaves, E. L., \& Damico, A. (2015). Medicaid's role for people with dementia. Kaiser Family Foundation (KFF). https://www.kff.org/medicaid/issue-brief/medicaids-rolefor-people-with-dementia/

Hale, J. M., Schneider, D. C., Mehta, N. K., \& Myrskylä, M. (2020). Cognitive impairment in the U.S.: Lifetime risk, age at onset, and years impaired. SSM - Population Health, 11, 100577100577. https://doi.org/10.1016/j.ssmph.2020.100577

Han, J. H., Bryce, S. N., Ely, E. W., Kripalani, S., Morandi, A., Shintani, A., Jackson, J. C., Storrow, A. B., Dittus, R. S., \& Schnelle, J. (2011). The effect of cognitive impairment on the accuracy of the presenting complaint and discharge instruction comprehension in older emergency department patients. Annals of Emergency Medicine, 57(6), 662-671.e2. https://doi.org/10.1016/j. annemergmed.2010.12.002

•Hansen, E. C., Hughes, C., Routley, G., \& Robinson, A. L. (2008). General practitioners' experiences and understandings of diagnosing dementia: Factors impacting on early diagnosis. Social Science \& Medicine, 67(11), 1776-1783. https://doi.org/10. 1016/j.socscimed.2008.09.020

Hawker, S., Payne, S., Kerr, C., Hardey, M., \& Powell, J. (2002). Appraising the evidence: Reviewing disparate data systematically. Qualitative Health Research, 12(9), 1284-1299. https:// doi.org/10.1177/1049732302238251

Hodgson, J., Lamson, A., Mendenhall, T., \& Crane, R. (2014). Medical family therapy: Advanced applications. Springer.

Hurd, M. P., Delavande, A., Mullen, K. J., \& Langa, K. M. (2013). Monetary costs of dementia in the United States. New England 
Journal of Medicine, 368(14), 1326-1334. https://doi.org/10. 1056/NEJMsa1204629

Institute of Medicine. (2001). Crossing the quality chasm: A new health system for the 21st century. National Academy Press.

Institute for Patient- and Family- Centered Care (n.d.) Core Concepts of Patient- and Family-Centered Care. https://www.ipfcc.org/ about/pfcc.html

Jazieh, A. R., Volker, S., \& Taher, S. (2018). Involving the family in patient care: A culturally tailored communication model. Global Journal on Quality and Safety in Healthcare, 1(2), 33-37. https://doi.org/10.4103/JQSH.JQSH_3_18

Jennings, L. A., Palimaru, A., Corona, M. G., Cagigas, X. E., Ramirez, K. D., Zhao, T., Hays, R. D., Wenger, N. S., \& Reuben, D. B. (2017). Patient and caregiver goals for dementia care. Quality of Life Research, 26(3), 685-693. https://doi.org/10. 1007/s11136-016-1471-7

Johnson, B. H., \& Abraham, M. R. (2012). Partnering with Patients, Residents, and Families: A Resource for Leaders of Hospitals, Ambulatory Care Settings, and Long-Term Care Communities (pp. 169-180). Institute for Patient- and Family-Centered Care.

-Judge, K. S., Bass, D. M., Snow, A. L., Wilson, N. L., Morgan, R., Looman, W. J., McCarthy, C., \& Kunik, M. E. (2011). Partners in dementia care: A care coordination intervention for individuals with dementia and their family caregivers. The Gerontologist, 51(2), 261-272. https://doi.org/10.1093/geront/gnq097

Kokorelias, K. M., Gignac, M. A. M., Naglie, G., \& Cameron, J. I. (2019). Towards a universal model of family centered care: A scoping review. BMC Health Services Research, 19(1), 564-574. https://doi.org/10.1186/s12913-019-4394-5

Kotagal, V., Langa, K. M., Plassman, B. L., Fisher, G. G., Giordani, B. J., Wallace, R. B., Burke, J. R., Steffens, D. C., Kabeto, M., Albin, R. L., \& Foster, N. L. (2015). Factors associated with cognitive evaluations in the United States. Neurology, 84(1), 64-71. https://doi.org/10.1212/WNL.0000000000001096

Langa, K. M., \& Levine, D. A. (2014). The diagnosis and management of mild cognitive impairment: A clinical review. JAMA: The Journal of the American Medical Association, 312(23), 2551-2561. https://doi.org/10.1001/jama.2014.13806

Lin, J. S., O'Connor, E., Rossom, R. C., Perdue, L. A., Burda, B. U., Thompson, M., \& Eckstrom, E. (2013). Screening for cognitive impairment in older adults: An evidence update for the U.S. Preventive Services Task Force. Preventive Services Task Force. Agency for Healthcare Research and Quality (US). https://pubmed.ncbi.nlm.nih.gov/24354019/

Lugo-Palacios, D. G., \& Gannon, B. (2017). Health care utilisation amongst older adults with sensory and cognitive impairments in Europe. Health Economics Review, 7(1), 1-15. https://doi.org/ 10.1186/s13561-017-0183-1

Maslow, K., \& Fortinsky, R. H. (2018). Nonphysician care providers can help to increase detection of cognitive impairment and encourage diagnostic evaluation for dementia in community and residential care settings. The Gerontologist, 58(S1), S20-S31. https://doi.org/10.1093/geront/gnx171

McDaniel, S. H., Hepworth, J., \& Doherty, W. J. (1992). Medical family therapy: A biopsychosocial approach to families with health problems. Basic Books. https://psycnet.apa.org/record/ 1992-98536-000

McDaniel, S. H., Doherty, W. J., \& Hepworth, J. (2014). Medical family therapy and integrated care (2nd ed.). American Psychological Association Publications.

McDaniel, S. H., Grus, C. L., Cubic, B. A., Hunter, C. L., Kearney, L. K., Schuman, C. C., Karel, M. J., Kessler, R. S., Larkin, K. T., McCutcheon, S., Miller, B. F., Nash, J., Qualls, S. H., Connolly, K. S., Stancin, T., Stanton, A. L., Strum, L. A., \& Johnson, S. B. (2014b). Competencies for psychology practice in primary care. The American Psychologist, 69(4), 409-429. https://doi. org/10.1037/a0036072

Mendenhall, T., Lamson, A., Hodgson, J., \& Baird, M. (Eds.). (2018). Clinical methods in medical family therapy. UK: Springer.

Miled, Z. B., Haas, K., Black, C. M., Khandker, R. K., Chandrasekaran, V., Lipton, R., \& Boustani, M. A. (2020). Predicting dementia with routine care EMR data. Artificial Intelligence in Medicine. https://doi.org/10.1016/j.artmed.2019.101771

Millenson, M. L., Shapiro, E., Greenhouse, P. K., \& DiGioia, A. M. (2016). Patient- and Family-Centered Care: A Systematic Approach to Better Ethics and Care. AMA Journal of Ethics, 18(1), 49-55. https://doi.org/10.1001/journalofethics.2017.18.1. stas $1-1601$

Miller, B. F., Mendenhall, T. J., \& Malik, A. D. (2009). Integrated primary care: An inclusive three-world view through process metrics and empirical discrimination. Journal of Clinical Psychology in Medical Settings, 16, 21-30. https://doi.org/10.1007/ s10880-008-9137-4

Miller, B. F., Ross, K. M., Davis, M. M., Melek, S. P., Kathol, R., \& Gordon, P. (2017). Payment reform in the patient-centered medical home: Enabling and sustaining integrated behavioral health care. The American Psychologist, 72(1), 55-68. https://doi.org/ 10.1037/a0040448

Moher, D., Liberati, A., Tetzlaff, J., Altman, D. G., \& The PRISMA Group. (2009). Preferred reporting items for systematic reviews and meta-analyses: The PRISMA statement. PLoS Medicine, 6(7), e1000097. https://doi.org/10.1371/journal.pmed1000097

•Nichols, L. O., Martindale-Adams, J., Burns, R., Graney, M. J., \& Zuber, J. (2011). Translation of a dementia caregiver support program in a health care system-REACH VA. Archives of Internal Medicine, 171(4), 353-359. https://doi.org/10.1001/ archinternmed.2010.548

Nicosia, F. M., Spar, M. J., Steinman, M. A., Lee, S. J., \& Brown, R. T. (2019). Making function part of the conversation: Clinician perspectives on measuring functional status in primary care. Journal of the American Geriatrics Society., 67(3), 493-502. https://doi.org/10.1111/jgs.15677

Pathak, K. P., \& Montgomery, A. (2015). General practitioners' knowledge, practices, and obstacles in the diagnosis and management of dementia. Aging \& Mental Health, 19(10), 912-920. https:// doi.org/10.1080/13607863.2014.976170

Peek, C. J. (2008). Planning care in the clinical, operational, and financial worlds. In R. Kessler \& D. Stafford (Eds.), Collaborative medicine case studies: Evidence in practice. Springer.

•Philp, I. \& Young, J. (1988). Audit of support given to lay carers of the demented elderly by a primary care team. Journal of the Royal College of General Practitioners, 38(309), 153-155.https://www. ncbi.nlm.nih.gov/pmc/articles/PMC1711307/

$\bullet$ Reuben, D. B., Roth, C. P., Frank, J. C., Hirsch, S. H., Katz, D., McCreath, H., Younger, J., Murawski, M., Edgerly, E., Maher, J., Maslow, K., \& Wenger, N. S. (2010). Assessing care of vulnerable elders - Alzheimer's disease: A pilot study of a practice redesign intervention to improve the quality of dementia care. Journal of the American Geriatric Society (JAGS), 58(2), 324329. https://doi.org/10.1111/j.1532-5415.2009.02678.x

-Sato, S., Kazui, H., Shimizu, Y., Yoshida, T., Yoshiyama, K., Kanemoto, H., Suzuki, Y., Morikami, T., Fujisue, H., Tanaka, T., \& Ikeda, M. (2018). Usefulness of carer-held records to support informal caregivers of patients with dementia who live at home. Psychogeriatrics, 18(3), 166-174. https://doi.org/10.1111/ psyg. 12304

Schmidt., K. L., Lingler, J. H., \& Schulz, R. (2009). Verbal communication among Alzheimer's disease patients, their caregivers, and primary care physicians during primary care office visits. Patient Education and Counseling, 77(2), 197-201. https://doi. org/10.1016/j.pec.2009.03.023 
Seematter-Bagnoud, L., \& Büla, C. (2018). Brief assessments and screening for geriatric conditions in older primary care patients: A pragmatic approach. Public Health Reviews, 39(1), 8. https:// doi.org/10.1186/s40985-018-0086-7

-Shega, J. W., Levin, A., Hougham, G. W., Cox-Hayley, D., Luchins, D., Hanrahan, P., Stocking, C., \& Sachs, G. A. (2003). Palliative Excellence in Alzheimer Care Efforts (PEACE): A program description. Journal of Palliative Medicine, 6(2), 315-320. https://doi.org/10.1089/109662103764978641

Sivananthan, S. N., Puyat, J. H., \& McGrail, K. M. (2013). Variations in self-reported practice of physicians providing clinical care to individuals with dementia: A systematic review. Journal of the American Geriatrics Society, 61(8), 1277-1285. https://doi.org/ $10.1111 /$ jgs. 12368

Skibitsky, M., Poll, J., Garrett, K., Obray, C., Fotheringham, J., \& Hoesch, R. (2016). P3-339: Support for cognitively impaired patients is a top primary care need. Alzheimer's \& Dementia. https://doi.org/10.1016/j.jalz.2016.06.2004

Smith, E., \& Wright, C. B. (2021). Etiology, clinical manifestations, and diagnosis of vascular dementia. In Yaffe, K., \& Kasner, S. E. (Eds.), UptoDate. Retrieved September 30, 2021, from https:// www.uptodate.com/contents/etiology-clinical-manifestationsand-diagnosis-of-vascular-dementia

St-Hilaire, A., Hudon, C., Preville, M., \& Potvin, O. (2017). Utilization of healthcare services among elderly with cognitive impairment no dementia and influence of depression and anxiety: A longitudinal study. Aging and Mental Health, 21(8), 810-822. https:// doi.org/10.1080/13607863.2016.1161006

-Teel, C. S. (2004). Rural practitioners' experiences in dementia diagnosis and treatment. Aging \& Mental Health, 8(5), 422-429. https://doi.org/10.1080/13607860410001725018

United States Census (2018). The Population 65 Years and Older in the United States: 2016. https://www.census.gov/content/dam/ Census/library/publications/2018/acs/ACS-38.pdf

•Vick, J. B., Amjad, H., Smith, K. C., Boyd, C. M., Gitlin, L. N., Roth, D. L., Roter, D. L., \& Wolff, J. L. (2018). "Let him speak:" A descriptive qualitative study of the roles and behaviors of family companions in primary care visits among older adults with cognitive impairment. International Journal of Geriatric Psychiatry, 33(1), e103-e112. https://doi.org/10.1002/gps.4732

-Werner, P., Gafni, A., \& Kitai, E. (2004). Examining physicianpatient-caregiver encounters: The case of Alzheimer's disease patients and family physicians in Israel, Aging \& Mental Health, 8(6), 498-504. https://doi.org/10.1080/13607860412331303793

-Werner, P. (2006). Family physicians' recommendations for the treatment of Alzheimer's disease. American Journal of Alzheimer's Disease \& Other Dementias, 21(6), 403-410. https://doi.org/10. $1177 / 1533317506294844$

Wolff, J. L., \& Roter, D. L. (2011). Family presence in routine medical visits: A meta-analytical review. Social Sciences Medicine, 72(6), 823-831. https://doi.org/10.1016/j.socscimed.2011.01. 015

Wolff, J. L., Spillman, B. C., Freedman, V. A., \& Kasper, J. D. (2016). A national profile of family and unpaid caregivers who assist older adults with health care activities. Journal of the American Medical Association Internal Medicine., 176(3), 372-379. https://doi.org/10.1001/jamainternmed.2015.7664

Wong, P., Redley, B., Digby, R., Correya, A., \& Bucknall, T. (2019). Families' perspectives of participation in patient care in an adult intensive care unit: A qualitative study. Australian Critical Care: Official Journal of the Confederation of Australian Critical Care Nurses, 33(4), 317-325. https://doi.org/10.1016/j.aucc.2019.06. 002

Wübbeler, M., Thyrian, J. R., Michalowsky, B., Erdmann, P., Hertel, J., Holle, B., Gräske, J., Schäfer-Walkmann, S., \& Hoffmann, W. (2017). How do people with dementia utilise primary care physicians and specialists within dementia networks? Results of the Dementia Networks in Germany (DemNet-D) study. Health and Social Care in the Community, 25(1), 285-294. https://doi. org/10.1111/hsc.12315

Publisher's Note Springer Nature remains neutral with regard to jurisdictional claims in published maps and institutional affiliations. 